\title{
EIS Analysis on Stress Corrosion Initiation of Pipeline Steel under Disbonded Coating in Near-neutral pH Simulated Soil electrolyte
}

\author{
Maocheng YAN*, Jin XU, Libao YU, Tangqing WU, Cheng SUN, Wei KE \\ Environmental Corrosion Center, Institute of Metal Research, Chinese Academy of Sciences \\ Shenyang 110016, China
}

\begin{abstract}
Initiation of stress corrosion of X80 high strength low alloy (HSLA) pipeline steel in a near-neutral $\mathrm{pH}$ environment was investigated in a crevice cell simulating coating disbondment. Multi specimens were loaded simultaneously by a loading frame. EIS was applied to characterize behavior of SCC and local electrochemical process. Results indicate that the steel under disbonded coating is in an active dissolution state. In-depth profile of the reciprocal charge transfer resistance shows a decreasing trend over distance from the opening. A shielding factor was proposed to characterize shielding effect of disbondment on stress corrosion of pipeline steels.
\end{abstract}

Keywords: A. Carbon steel; C. Stress corrosion; B. EIS; B. SEM; C. Crevice corrosion

\footnotetext{
${ }^{*}$ Corresponding author.

Email: Yanmc@imr.ac.cn; Tel. (+86) 242391 3195; Fax (+86) 2423894149.
} 


\section{Introduction}

Combination of coating and cathodic protection $(\mathrm{CP})$ is generally designed for corrosion control of buried steel pipelines. The coating is the primary corrosion control system, while $\mathrm{CP}$ is a complementary protection system aimed at preventing corrosion at coating defects, where the pipe steel is exposed to the electrolytic environment. However, corrosion and stress corrosion cracking (SCC) occur under disbonded coatings, which may prevent access of cathodic protection current to steel. SCC under disbonded coating continues to be a big issue for integrity management of high pressure pipelines [1-8].

In recent years, three-layer polyethylene (3LPE) coatings have been being widely used on long-distance high pressure transmission pipelines in China, for instance, the West-to-East natural gas transmission project. The 3LPE coating tends to remain high insulating after disbonding from pipelines, and block CP current $[9,10]$. This performance is similar to PE tape coatings that caused SCC failure of pipeline after disbonding. Large scale disbondment have been reported for 3LPE coatings [11, 12]. Issues related to CP shielding, electrical interference (AC and DC) and SCC under disbondment have become concern because of the high integrity and dielectric strength of 3LPE coatings [13].

A trapped thin electrolyte layer is known responsible for SCC of high-strength low-alloy (HSLA) pipeline steel under disbonded coating [14-17], where the pipeline surface underlying cannot be protected by either coating or $\mathrm{CP}$. The thin electrolyte layer forms on pipeline surface as consequence of coating adhesion being lost and electrolytes penetrating into the crevice of disbonded area. The characteristic thin electrolyte layer environment derives from the surrounding soil environment under the function of coating type, failure mode, disbondment geometry, soil environment and applied CP [5, 14, 16, 18-21]. The $\mathrm{pH}$ of the local electrolyte may vary significantly from near-neutral $\mathrm{pH}(\sim 6.5)$ to high $\mathrm{pH}(\sim 9.5)$, depending on the availability of $\mathrm{CP}$ current and $\mathrm{CO}_{2}$ level $[16,20]$.

A significant amount of research has been performed to reproduce the near-neutral $\mathrm{pH}$ $\mathrm{SCC}$ (NNpH SCC) in laboratory for the purpose of ascertaining the cause or mechanism and identifying the primary controlling factors. Most of these studies were conducted in bulk 
solution condition purging $\mathrm{CO}_{2}[22,23]$. However, $\mathrm{SCC}$ initiates and proceeds under thin electrolyte layers, which is generally characterized by colonies of small, shallow cracks on outside pipeline surface. Corrosion of pipeline steel in the thin electrolyte layer under disbonded coating is a complicated and specific phenomenon. Concentration cells may be established in the thin electrolyte layer in terms of concentration gradient of various species, such as $\mathrm{CO}_{2}, \mathrm{HCO}_{3}{ }^{-}$and $\mathrm{H}^{+}$, which appear to exert a significant influence on the local corrosion process $[17,23]$. The bulk solution methodology neglects various concentration cells under coating disbondment. Improvement in measurement techniques and more realistic test conditions would be helpful to further understand the mechanism of SCC initiation, and to identify the primary controlling factors of $\mathrm{NNpH} \mathrm{SCC.}$

Electrochemical measurements in the local environment under disbanded coating have been challenging because of high ohmic drop (IR) in the thin electrolyte layer. Errors may occur from the high IR drop between reference electrode and working electrode and non-uniform current distribution over the working electrode [18, 24].

Initiation of stress corrosion of high strength low alloy (HSLA) pipeline steel under disbonded coating has been highlighted in our resent research. In a previous paper, SCC initiation of X80 steel was reported under disbondment in an acidic soil environment [17]. It was found that corrosion profile is distinctly influenced by the coating disbondment. Pitting and micro crack along grounding lines appear on tensile specimen at the opening, whereas corrosion attack mitigates under disbondment. However, the thin crevice gap distance $(1 \mathrm{~mm})$ used in the previous paper was found limited for application of EIS measurement.

The present paper highlights application of EIS measurement for monitoring kinetics of electrochemical process for both tensile specimen and unstressed specimen under disbondment. A 5-mm gap crevice was formed between X80 steel surface and the shielding plate simulating disbondment. Kinetics of corrosion process was acquired to characterize the corrosion scenarios and SCC initiation under disbonded coating. We desire to complement methodology of corrosion under disbonded coating by using electrochemical impedance spectroscopy (EIS). 


\section{Experimental}

\subsection{Specimens and test solution}

The material used in this work was API grade X80 HSLA pipeline steel with chemical composition listed in Table 1. Yield strength (YS) and ultimate tensile strength of the steel are 581 and $655 \mathrm{MPa}$, respectively. Geometry of the tensile specimen is shown in Fig. 1. The working surfaces were abraded parallel to the loading direction using 400-1000 grit emery papers, followed by rinsing with acetone and alcohol.

The electrolyte solution was the NS4 solution, a simulated trapped electrolyte with compositions as follows: $0.122 \mathrm{~g} / \mathrm{L}(1.64 \mathrm{mmol} / \mathrm{L}) \mathrm{KCl}, 0.483 \mathrm{~g} / \mathrm{L}(5.75 \mathrm{mmol} / \mathrm{L}) \mathrm{NaHCO}_{3}$, $0.181 \mathrm{~g} / \mathrm{L}(1.23 \mathrm{mmol} / \mathrm{L}) \mathrm{CaCl}_{2} \cdot 2 \mathrm{H}_{2} \mathrm{O}$ and $0.131 \mathrm{~g} / \mathrm{L}(0.740 \mathrm{mmol} / \mathrm{L}) \mathrm{MgSO}_{4} \cdot 7 \mathrm{H}_{2} \mathrm{O}$.

\subsection{Experimental condition and procedure}

A crevice cell (simulating coating disbondment) equipped with a multi-sample loading frame have been specifically designed for studying stress corrosion of pipeline steel under disbonded coating. They are schematically shown in Fig. 2. Detail description of the experimental set-up can be found in our previous paper [17]. In brief, the crevice was formed by bolting PTFE gasket between a shielding PMMA plate and a base PMMA plate with stand-alone specimens attached. In this system, the gap distance was adjustable controlled by the PTFE gasket. A gap distance of $5 \mathrm{~mm}$ was used in this work. The length of the crevice was $25 \mathrm{~cm}$, forming a narrow, deep geometry with a depth/width ratio of 50 . The electrolyte inside the shielding simulates the local environment trapped under the coating disbondment. At the bottom of the bulk solution container, a rectangular open mouth was opened through the shielding plate to serve as a coating defect (holiday). The shielding plate and the base plate were bolted and the shielding area was properly sealed to avoid $\mathrm{O}_{2}$ ingression.

Eight stand-alone specimens in four couples (four tensile specimens and four unstressed specimens) were glued to the base plate in parallel along the shielding crevice. The stand-alone specimens were $5 \mathrm{~mm}$ wide along the crevice, and only the upside of the specimen was exposed to the crevice, giving a work surface of $0.5 \times 6 \mathrm{~cm}^{2}$. The rest spaces 
between specimens on the base plate were patched by auxiliary plates made with the same steel. The adjacent specimens were insulated electrically each other by a $1 \mathrm{~mm}$ thickness gap filled with silicone rubber. All the steel specimens and plates were electrically connected through the parallel wire, which made them work as one single body of pipeline steel under disbonded coating. The tensile specimens were loaded simultaneously by the loading frame assembled to the crevice cell. The level of loading applied for tensile specimens was $100 \%$ yield strength (YS).

For convenience, the specimen couple at the opening was subsequently referred to as $\mathrm{S}_{\mathrm{ys}}-0$ and $\mathrm{S}_{0}-0$ for the tensile specimen and the unstressed specimen, respectively, and the couple $25 \mathrm{~cm}$ from the opening was labeled as $\mathrm{S}_{\mathrm{ys}}-25$ and $\mathrm{S}_{0}-25$, respectively.

All experiments in this work were carried out at free corrosion condition at room temperature. The bulk soil solution was continuously sparged with $5 \% \mathrm{CO}_{2} / \mathrm{N}_{2}$ throughout the test and kept a constant $\mathrm{CO}_{2}$ partial pressure $\left(p_{\mathrm{CO} 2}\right)$ to simulate the atmospheric condition in soil environments. The conductivity of the bulk electrolyte saturated with $5 \% \mathrm{CO}_{2} / \mathrm{N}_{2}$ was $950 \mu \mathrm{S} / \mathrm{cm}$.

\subsection{Electrochemical measurement}

EIS was employed to explore the corrosion process of the stand-alone specimen under disbonded coating. For the measurement, the stand-alone specimen was disconnected from the parallel line and EIS was measured one by one along the crevice. EIS measurements were conducted by an EG\&G PAR potentiostat/galvanostat 2273 using a traditional three-electrode system. The stand-alone specimen was used as the working electrode. A saturated calomel electrode (SCE) through the Luggin capillary in the measurement port was used as the reference electrode. All the other steel surfaces in the crevice were electrically connected through the parallel wire to serve as the counter electrode. EIS was acquired at open circuit potential (OCP) over the frequency range of $10^{-2} \sim 10^{4} \mathrm{~Hz}$ using an AC signal with the amplitude of $10 \mathrm{mV}$ (rms). EIS data was analyzed by ZSimpWin software (Princeton Applied Research). 
Local potential was monitored by SCE electrode through the Luggin capillary. The $\mathrm{pH}$ was recorded by a tungsten wire $\mathrm{pH}$ microelectrode with a $1 \mathrm{~mm}$ tip. Preparation of the $\mathrm{pH}$ microelectrode was described thoroughly in [25]. The real ohmic resistance can be obtained from the high frequency limit of the Bode EIS plot.

\subsection{Validity of EIS measurement}

For EIS measurement in the thin electrolyte layer under the shielding plate, stability of the test system is crucial to obtain reliable EIS data [26]. In this work, stability of the test system and validity of EIS measurement were checked by several methods including the hysteresis between the spectra acquired by high-to-low and low-to-high frequency sweeps, the spectra acquired at different amplitudes of the AC signal between 2 and $20 \mathrm{mV}$ (rms) and $\mathrm{K}-\mathrm{K}$ transform test based on the procedure of Boukamp [27].

EIS plots acquired by high-to-low and low-to-high frequency sweeps almost exactly coincide. Good agreement is also observed between the spectra acquired at different amplitudes of the AC signal between 5 and $20 \mathrm{mV}$ (rms). These EIS plots are not shown in this paper.

The impedance is defined within Linear System Theory (LST). According to constraints of LST, linearity, causality and stability constraints must be satisfied for a system for validity of EIS measurements [26]. The K-K transform is a convenient method to validate the measured EIS and examine the system with respect to causality, linearity, and stability constraints [28-30]. The conventional equations for K-K transform have proposed by Macdonald et al [26, 29].

A set of experimental EIS data measured at the beginning and at the end of the test are shown in Fig. 3, along with their K-K transforms plotted as fitting lines superimposed on the measured data. The experimental and the transformed data for both the real and the imaginary components coincide remarkably, except for some disorder data points of measured EIS data. The similar agreement level is found for all EIS data in this work. The agreement between the experimental data and the transformed data indicates that the tested system under investigation satisfies LST constraints. 


\subsection{SEM image}

After the experiment, the specimens were unloaded and retrieved carefully from the crevice cell, rinsed with ethanol and dried in cool air flow. To remove corrosion product, the retrieved specimens were pickled in $6 \mathrm{~mol} / \mathrm{L}$ hydrochloric acid $(\mathrm{HCl})$ solution containing $20 \mathrm{~g} / \mathrm{L}$ hexamethylenetetramine (urotropine) as inhibitor. The surface of specimens after corrosion products removed was analyzed using scanning electron microscopy (SEM, Philips FEG XL30).

\section{Results}

\subsection{Local environment under the disbonded coating}

The profile of local potential for X80 steel at different positions under disbonded coating is plotted in Fig. 4. The potential of the steel under disbonded coating is $c a .-772 \mathrm{mV}$ vs SCE at the beginning of the test and shows a general trend of positive shifting over the test time. No significant difference is detected for the local potential among specimens under disbonded coating.

The behavior of the local potential is quite different from the results for a more occluded crevice (1 mm gap) in our previous work [17]. Under a 1-mm gap, the local potential shows a trend of positive shifting over the distance away from the opening [17]. This difference indicates that the gap distance is the critical factor influencing the OCP potential. The gap distance functions through affecting diffusion of species, like $\mathrm{CO}_{2}, \mathrm{HCO}_{3}{ }^{2-}$ and $\mathrm{Fe}^{2+}$, under the shielding.

The $\mathrm{pH}$ of the thin layer local environment at different positions under disbonded coating is shown in Fig. 5. The pH of the bulk NS4 solution is about 6.8 after continuously sparging 5\% $\mathrm{CO}_{2} / \mathrm{N}_{2}$ mixture gas. As can be seen, the $\mathrm{pH}$ under disbonded coating maintains near neutral (between 6.8 and 7.1) during the test period.

\subsection{EIS results}

This test system makes it possible to conduct electrochemical measurement for the individual specimen with or without stress at different locations under disbonded coating. 
Consequently, some electrochemical corrosion kinetics can be acquired to characterize corrosion scenarios and SCC initiation under disbonded coating.

EIS diagrams measured for specimens with or without stress after 1, 15, 80 and 120 day test at different locations are presented in a series of figures (Fig. 6-9). The equivalent electrical circuit $R(Q R)$ shown in Fig. 10 was used to fit the measured data, and the fitted line are presented along with the measured data in points. The more details of the equivalent electrical circuit are addressed further in the next section.

EIS diagrams for the tensile specimen and the unstressed specimen show the similar features. All the Nyquist plots show a well-defined depressed capacitive arc indicating the frequency dispersion effect that is common for the solid metal electrode. Only a single time constant can be observed from the Bode phase angle plots. The phase shift $\theta$ goes further than $-45^{\circ}$, and the current distribution profile over the working electrode can be considered uniform for the EIS measurement in this test condition and the change transfer resistance can be determined from impedance at the low frequency [24].

Kinetics of the electrochemical process can be identified and quantified form the low frequency impedance [31, 32]. Generally, for EIS measured on bare steel samples, the charge transfer resistance at the steel/interface dominates the impedance at low frequencies, $|Z|_{\mathrm{LF}}$, (the Nernst impedance), while the solution resistance dominates the impedance at high frequencies, $|Z|_{\mathrm{HF}}$. Extrapolation of the low frequency impedance can be used to estimate the charge transfer resistance.

The intact semicircle shows that the steel surface under disbonded coating is in active dissolution state and the electrochemical process is under charge transfer control. Fig. 6 (measured after 1 day) clearly demonstrates that, for the same specimen, the capacitive arc (Fig. 6 a) becomes larger and the corresponding $|Z|_{\mathrm{LF}}$ (Fig. 6 b) markedly increase with distance from the opening, indicating that the electrochemical process is suppressed under disbonded coating. The phase angle for specimens under disbonded coating tends to increase with distance from the opening (Fig. $6 \mathrm{c}$ ). 
At the same position, the impedance for the tensile specimen is apparently lower over all the frequencies compared with that for the unstressed specimen. $|Z|_{L F}$ for the tensile specimen markedly decreases, indicating that the corrosion process is enhanced by applied stress. The similar features can also be identified from all the EIS diagrams in Fig. 7, Fig. 8 and Fig. 9.

Figures 6-9 also demonstrate that both the capacitive arc and the resultant $|Z|_{L F}$ decrease gradually for the same specimen during the period of test, indicating that electrochemical processes are suppressed over the test period.

\subsection{Further analysis on EIS data}

The equivalent electrical circuit $R(Q R)$ shown in Fig. 10 was used to fit the EIS data. The equivalent electrical circuit consists of the solution resistance $R_{\mathrm{s}}$, the charge transfer resistance $R_{\mathrm{ct}}$, and a constant phase element (CPE) $Q_{\mathrm{dl}}$ is used as a substitute of the double layer capacitance $C_{\mathrm{dl}}$ at the metal/electrolyte interface because of the nonideal capacitive response of the interface. The CPE $Q$ is defined as $[33,34]$ :

$$
Z_{Q}(\omega)=\left[Y_{0}(j \omega)^{\mathrm{n}}\right]^{-1}
$$

where $\omega$ is the angular frequency, $Y_{0}$ the $\mathrm{CPE}$ constant (admittance magnitude of CPE) which can be converted into a capacitance, and $n$ the $Q$-power $(0<n \leq 1)$.

As can be seen from Figs. 6-9, the equivalent electrical circuit provided a reliable description for the corrosion systems. The electrical element parameters obtained from fitting the measured EIS data using the equivalent electrical circuit in Fig. 10 are summarized in Table 2. $R_{\text {ct }}$ value for various specimens is plotted in Fig. 11 as a function of distance from the opening $(d)$. It clearly shows that, at the beginning of the test, $R_{\mathrm{ct}}$ at different positions shows the similar value, because of the similar initial electrolyte situation. $R_{\mathrm{ct}}$ of the tensile specimens under disbonded coating is significantly higher than that at the opening. After $15 \mathrm{~d}$ of test, $R_{\mathrm{ct}}$ under disbonded coating area increases with distance from the opening, indicating that the electrochemical reaction process is suppressed by the coating disbondment. Meanwhile, $R_{\mathrm{ct}}$ shows a increasing trend over the test period, which can be attributed to evolution of the local environment and formation of corrosion products.

Evolution of kinetics of electrochemical processes involved can be quantified form $R_{\mathrm{ct}}$ and 
$Q_{\mathrm{dl}}[31,32]$. The reciprocal charge transfer resistance (the charge transfer conductance), $R_{\mathrm{ct}}^{-1}$, is proportional to the corrosion rate of the steel through the Stern-Geary equation. $R_{\mathrm{ct}}^{-1}$ for X80 steel is plotted in Fig. 12 as a function of distance from the opening $(d)$. At 1 day, no remarkable difference is detected for $R_{\mathrm{ct}}^{-1}$ at different positions under the disbonded coating, this can be explained by the fact that specimens at all positions under disbonded coating was contacted with the similar electrolyte situation (the fresh NS4 solution) at the beginning of the test. However, with increasing test period, the specimen at the opening shows the highest $R_{\mathrm{ct}}^{-1}$, and the $R_{\mathrm{ct}}^{-1}-d$ plots show clear decreasing trends over distance from the opening, for both the tensile specimen and the unstressed specimen. The distribution profile of $R_{\mathrm{ct}}^{-1}$ can be attributed to existence of the $\mathrm{CO}_{2}$ concentration gradient that was gradually established over the distance from opening. The $R_{\mathrm{ct}}^{-1}-d$ plot shifts to the low value direction over the test period, indicating that $R_{\mathrm{ct}}^{-1}$ decreases over the time. It can be attributed, at least partially, to development and existence of the concentration cell under the shielding, especially the accumulation of $\mathrm{Fe}^{2+}$ and formation of corrosion products. For the specimen couple at the same location, $R_{\mathrm{ct}}^{-1}$ for the tensile specimen is obviously higher than that for the unstressed specimen, which reflects the mechanochemical effect of the tensile stress applied.

It should be noted that the EIS plots show active dissolution state of the local steel surface under disbonded coating. Any diffusion process of species in the crevice cannot be identified from the EIS plots under the shielding. But, some clue of the species diffusion can be obtained through comparing the EIS plots at different position.

\subsection{Stress cell under disbonded coating}

This test system also enabled us to measure the galvanic current from stress cell in the thin electrolyte layer under disbonded coating. Stress cell can form between the couple of the tensile specimen and the unstressed specimen at different regions under disbonded coating, and resultant galvanic current occurs between them.

The galvanic current between the tensile specimen and the unstressed specimen inside the shielding are plotted in Fig. 13. The galvanic current in range of $0.5-2 \mu \mathrm{A} / \mathrm{cm}^{2}$ is detected between the specimens at different positions. Herein, the positive current signifies the anode 
for the tensile specimen. As can be seen, a galvanic current exists between the tensile specimen and the unstressed specimen under disbonded coating. The galvanic current declines with time and gradually reaches a relatively steady state. The tensile specimen with stress and strain is anodic to the unstressed specimen. This observation suggests that the stress-strain differential is important in causing micro-pitting and eventual SCC [35]. The stress cell leads to enhanced anodic dissolution and development of discontinuities at the surface.

\subsection{Corrosion scenarios under disbonded coating}

SEM micrograph (Fig.14) reveals a loose and porous corrosion product layer on the steel surfaces after the test. The corrosion product layer becomes thinner from the opening to the disbonded area. After corrosion products removed, SEM morphologies for unstressed specimens at different positions (Fig. 15) show that general corrosion dominates surface attack of the unstressed specimen, and corrosion severity becomes slight under disbonded coating away from the opening, which is consistent with the results from EIS measurements.

Some typical SEM micrographs of tensile specimens $5 \mathrm{~cm}$ and $25 \mathrm{~cm}$ away from the opening under disbonded area are presented in Fig. 16. As can be seen, general corrosion is limited and pitting attack becomes dominant surface attack under disbonded coating $5 \mathrm{~cm}$ away from the opening (Fig. 16 a, b). With the size and number increasing during the long term test, some pits occur in clusters and coalesce with each other forming coalesced pitting. Colonies of small, shallow cracks are observed on the surface of the tensile specimen at 25 cm away from the opening (Fig. $16 \mathrm{c}, \mathrm{d}$ ).

\section{Discussion}

As indicated by electrolyte samples collected from pipe surfaces under disbonded coating in the field, dilute ground waters of relatively low $\mathrm{pH}(\sim 6.5)$ containing $\mathrm{CO}_{2}$ are characteristic environments that favor $\mathrm{NNpH} \mathrm{SCC[20].} \mathrm{The} \mathrm{condition} \mathrm{is} \mathrm{general} \mathrm{found} \mathrm{under} \mathrm{disbonded}$ coating, where no significant amount of cathodic current reaches the steel, and the environment will remain near neutral $\mathrm{pH}$ depending upon the partial pressure of $\mathrm{CO}_{2}$. In 
anoxic soil conditions, dissolved $\mathrm{CO}_{2}$ is known as the most important environmental driving factor influencing anodic corrosion and NNpH SCC of pipeline steel $[8,14,22]$. The $\mathrm{CO}_{2}$ level in soil can be much higher as a result of microbial activities and plant root metabolism and the content shows seasonal fluctuation from 4 to 23\% [7], depending on temperature, soil moisture, and amount of organic matters.

Corrosion rate of pipeline steels tends to increase with $\mathrm{CO}_{2}$ level $[8,36,37] . \mathrm{CO}_{2}$ dissolves in groundwater forming a weak acid, i.e., carbonic acid $\left(\mathrm{H}_{2} \mathrm{CO}_{3}\right)$, which dissociates into $\mathrm{HCO}_{3}{ }^{-}$and $\mathrm{H}^{+}$as follows[16, 20]:

$\mathrm{CO}_{2}+\mathrm{H}_{2} \mathrm{O} \leftrightarrow \mathrm{H}_{2} \mathrm{CO}_{3}$

$\mathrm{H}_{2} \mathrm{CO}_{3} \leftrightarrow \mathrm{HCO}_{3}^{-}+\mathrm{H}^{+}$

Without CP current reaching the pipe surface, the electrolyte will keep near-neutral $\mathrm{pH}(6-7)$ depending on $p_{\mathrm{CO} 2}$. Pipeline steel generally displays the active dissolution behavior in the groundwater responsible for $\mathrm{NNpH} \mathrm{SCC}$. The dominant cathodic reaction balanced anodic dissolution of pipeline steel is reduction of $\mathrm{H}_{2} \mathrm{CO}_{3}$ or $\mathrm{H}^{+}$.

$$
\begin{aligned}
& \mathrm{H}^{+}+e \leftrightarrow \mathrm{H}_{\mathrm{ads}} \\
& \mathrm{H}_{2} \mathrm{CO}_{3}+e \leftrightarrow \mathrm{HCO}_{3}{ }^{-}+\mathrm{H}_{\mathrm{ads}}
\end{aligned}
$$

With the presence of disbonded coating, corrosive species is shielded, at least partially, by the disbondment, and cannot fully penetrate through the deep geometry to reach steel surface under the disbondment. The concentration gradient of $\mathrm{CO}_{2}$ is considered to exist because $\mathrm{CO}_{2}$ is supplied only at the opening, and it was consumed by corrosion process of the steel under the shielding. The $\mathrm{CO}_{2}$ concentration tends to diminish gradually under disbondment over distance from the opening. However, the concentration gradient may be too low to be distinguished by the local potential and $\mathrm{pH}$, due to the low concentration and the larger gap used in this work.

Mass-transfer of $\mathrm{CO}_{2}$ related species through thin electrolyte layer with a narrow, deep geometry under disbonded coating becomes the rate-limiting step for corrosion process. In this case, only the specimen at the opening defect is directly exposed to the bulk 
environment, and special corrosion scenarios different from that in bulk condition are usually observed on pipeline surfaces under disbonded coating. Corrosion process under disbonded coating may involve many additional reactions and processes, including electrochemical reactions at the steel surface, species diffusion between the interface of steel and electrolyte layer, species diffusion and mass transfer through the crevice, migration processes due to establishment of potential gradient and homogenous chemical reactions.

\subsection{Quantitative analysis on shielding effect of coating disbondment}

The reciprocal charge transfer resistance, $R_{\mathrm{ct}}^{-1}$, is highest at the opening, and it shows an exponentially decreasing trend over distance from the opening (Fig. 12). It is existence of the coating disbondment on the steel surface that induces the difference in the charge transfer resistance. The shielding effect of disbonded coating can be reflected by a shielding factor, the ratio of $R_{\mathrm{ct}}$ of the specimens under the shielding to that at the opening:

$$
k=\frac{R_{\mathrm{ct}, 0}}{R_{\mathrm{ct}, \mathrm{d}}}
$$

where $R_{\mathrm{ct}, \mathrm{d}}, R_{\mathrm{ct}, 0}$ are the charge transfer resistance of specimens under the shielding and that at the opening.

The shielding factor for the tensile specimens and unstressed specimens at $15 \mathrm{~d}$ and $120 \mathrm{~d}$ are plotted in Fig. 17 as a function of the distance/width ratio $(\delta)$. As might be expected, the shielding factor decreases exponentially with the distance/width ratio over distance from the opening. For tensile specimens, the shielding factors are $c a 0.74,0.58$ and 0.51 at $\delta=10,26$ and 50, respectively, at 15 day, and they decrease to $0.65,0.52$ and 0.44 at 120 day. For unstressed specimens, the factors are $c a 0.7,0.57$ and 0.50 at $\delta=10,26$ and 50, respectively, at 15 day, and are $0.64,0.48$ and 0.44 at 120 day. All the values are below 1, indicating that the corrosion (anodic dissolution) rate under disbonded coating is markedly mitigated compared with that at the opening.

By the aid of the shielding factor, it is possible to roughly estimate corrosion under disbonded coating by the charge transfer resistance detected at the opening. As indicated from above results, $R_{\mathrm{ct}}^{-1}$ at the opening is approximately two times higher than that at the deep 
shielding area. This is consistent with the weight-loss data reported for X65 steel (without stress applied) under simulated disbondment with the gap distance in the range of 2-20 mm $[38,39]$. This analysis also substantially agrees with the growth rate of SCC reported by Egbewande et al [8]. The results display that the environmental factor of SCC at the opening can be three times higher than that farther from the opening.

It should be pointed out that the shielding factor depends on the occlusion extent of the disbondment which may be characterized by its depth/width ratio. In the experiment setup used in this work, the gap distance is found one of the most important parameter determining corrosion profile under disbondment. Under the condition of $5 \mathrm{~mm}$ gap distance used in this work, $R_{\mathrm{ct}}^{-1}$ follows an exponentially decreasing trend with increasing the distance from the opening. However, a weak linearly decreasing trend has been found when the gap distance was $10 \mathrm{~mm}$ [8]. As the gap distance becomes thinner, a sharp decrease of the corrosion rate can be expected with increasing distance from the opening. As can be speculated, the shielding effect tends to diminish or even disappear with increasing the gap distance. If the coating disbondment was otherwise absent, the species gradients would disappear, leading to the bulk condition.

\subsection{Corrosion profile under disbonded coating}

Evidenced by both EIS measurement and surface micrograph, X80 steel under disbonded coating is in active dissolution state. In this condition, the highest $R_{\mathrm{ct}}^{-1}$ is found to occur at the opening and corrosion attack is markedly relieved under the shielding. The similar results are also observed in laboratory experiments by A. Eslami [38] and Karina Chevil [39].

All the experiments manifest that anodic dissolution (corrosion attack) is markedly relieved under disbonded coating. Existence of $\mathrm{CO}_{2}$ gradient should be responsible for the specific corrosion scenarios. $\mathrm{CO}_{2}$ concentration tends to diminish gradually under disbonded coating over distance from the opening, resulting in less corrosion severity under disbondment.

The experimental observations appear inconsistent with field cases, where cluster of pitting or microcrack were usually observed on pipeline surfaces under disbonded coating [39, 
40]. This inconsistency can be explained by the fact that some amount of CP current can be achieved at the open defect, and corrosion of pipeline steel at the defect is inhibited. As a result, severe corrosion prefers to occur in the deep disbondment where $\mathrm{CP}$ current is completely blocked.

Corrosion and crack growth in the crack crevice were reported somehow similar with the gap between specimen surface and disbonded coating [8]. Inside crack crevice of $\mathrm{NNpH} \mathrm{SCC}$, $\mathrm{CO}_{2}$ gradient may induce electrochemical process as well as hydrogen concentration gradient that affect crack growth of pipeline steel. As a result, crack growth rates were found to be more significantly enhanced at the surface than in the depth direction, and the former is about two times higher than the latter [8].

\section{Conclusions}

Stress corrosion behavior of $\mathrm{X} 80$ pipeline steel was investigated in a neutral $\mathrm{pH}$ solution in a crevice cell with a multi-sample loading frame. This test system and specimen arrangement enabled us to conduct electrochemical measurements in the thin electrolyte layer environment simulating disbonded coating. EIS was applied to monitor kinetics of corrosion process for both tensile specimen and unstressed specimen under disbonded coating. In-depth profile of the reciprocal charge transfer resistance, $R_{\mathrm{ct}}^{-1}$, of pipeline steel is quantitatively analyzed through EIS measurement. The following conclusions can be obtained:

Evidenced by local EIS measurement, the steel under disbonded coating is in an active dissolution state. $R_{\mathrm{ct}}^{-1}$ of the steel is highest at the opening, and it shows an exponential decreasing trend over the distance from the opening. $R_{\mathrm{ct}}^{-1}$ at the opening is about two times higher than that at the deep shielding area. Corrosion under disbonded coating was directly affected by the gradient of corrosive species. $\mathrm{CO}_{2}$ gradient is responsible for the corrosion scenarios under disbonded coating. It is possible to roughly estimate corrosion severity of the steel with the aid of the shielding factor.

General corrosion dominates surface attack of the unstressed specimen, and the severity becomes slight under disbonded coating away from the opening. Localized corrosion 
becomes dominant surface attack under disbonded coating. Coalesced pitting, colonies of small, shallow cracks are observed on the surface of tensile specimen in the deep area of the disbonded coating.

\section{Acknowledgments}

The work was financially supported by National Science Foundation of China (Grant No. 51131001 and 51471176) and National RD Infrastructure and Facility Development Program of China (No. 2005DKA10400CT-2-02).

\section{References}

[1] N. Sridhar, D.S. Dunn, M. Seth, Application of a general reactive transport model to predict environment under disbonded coatings, Corrosion, 57 (2001) 598-613.

[2] S.A. Shipilov, I.L. May, Structural integrity of aging buried pipelines having cathodic protection, Engineering Failure Analysis, 13 (2006) 1159-1176.

[3] X.G. Li, D.W. Zhang, Z.Y. Liu, Z. Li, D. C.W., C.F. Dong, Materials science: Share corrosion data, Nature, 527 (2015) 441.

[4] L. Zhiyong, C. Zhongyu, L. Xiaogang, D. Cuiwei, X. Yunying, Mechanistic aspect of stress corrosion cracking of X80 pipeline steel under non-stable cathodic polarization, Electrochemistry Communications, 48 (2014) 127-129.

[5] M. Yan, J. Wang, E. Han, S. Cheng, W. Ke, Characteristic and evolution of thin layer electrolyte on pipeline steel under CP shielding disbonded coating, Acta Metallurgica Sinica, 50 (2014) $1137-1145$.

[6] N.E. Board, Stress corrosion cracking on canadian oil and gas pipelines, in, National Energy Board, Calgary, Alberta, 1996.

[7] A. Egbewande, W. Chen, R. Eadie, R. Kania, G. Van Boven, R. Worthingham, J. Been, Transgranular crack growth in the pipeline steels exposed to near-neutral $\mathrm{pH}$ soil aqueous solutions: Discontinuous crack growth mechanism, Corrosion Science, 83 (2014) 343-354.

[8] A. Egbewande, W. Chen, R. Eadie, R. Kania, G. Van Boven, R. Worthingham, J. Been, Surface Crack Growth Behavior of Pipeline Steel Under Disbonded Coating at Free Corrosion Potential in Near-Neutral pH Soil Environments, Metallurgical and Materials Transactions a-Physical 
Metallurgy and Materials Science, 45A (2014) 4946-4959.

[9] B.T.A. Chang, H. Jiang, H.-J. Sue, S. Guo, et al. , Disbondment mechanism of 3LPE pipeline coatings in: 17th International conference on pipeline protection 2007, pp. 247-256.

[10] C. Argent, D. Norman, Fitness For Purpose Issues Relating To Fbe And Three Layer Pe Coatings in: CORROSION 2005, 3-7 April, Houston, Texas NACE International, 2005.

[11] A.N. Moosavi, S.O. Al-Mutawwa, S.M.A. Balboul, M.R. Saady, Hidden Problems with Three Layer Polypropylene Pipeline Coatings, in: CORROSION NACE International, San Diego, California, 2006.

[12] E. Legghe, E. Aragon, L. Belec, A. Margaillan, D. Mélot, M. Roche, Loss of adhesion of three layers pipelines coatings under cathodic protection, in: 17th Pipeline Protection Conference, BHRG, Edinburg, UK, 2007.

[13] D. Mélot, G. Paugam, M. Roche, Disbondments of Pipeline Coatings and Their Effects on Corrosion Risks, Journal of Protective Coatings \& Linings, (2009) 18.

[14] M. Yan, J. Wang, E. Han, W. Ke, Local environment under simulated disbonded coating on steel pipelines in soil solution, Corrosion Science, 50 (2008) 1331-1339.

[15] S.Y. Li, Y.G. Kim, Y.T. Kho, T. Kang, Statistical approach to corrosion under disbonded coating on cathodically protected line pipe steel, Corrosion, 60 (2004) 1058-1071.

[16] E.A. Charles, R.N. Parkins, GENERATION OF STRESS-CORROSION CRACKING ENVIRONMENTS AT PIPELINE SURFACES, Corrosion, 51 (1995) 518-527.

[17] M. Yan, C. Sun, J. Xu, T. Wu, S. Yang, W. Ke, Stress corrosion of pipeline steel under occluded coating disbondment in a red soil environment, Corrosion Science, 93 (2015) 27-38.

[18] A.Q. Fu, X. Tang, Y.F. Cheng, Characterization of corrosion of X70 pipeline steel in thin electrolyte layer under disbonded coating by scanning Kelvin probe, Corrosion Science, 51 (2009) 186-190.

[19] M.C. Yan, J.Q. Wang, E.H. Han, W. Ke, Electrochemical measurements using combination microelectrode in crevice simulating disbonded of pipeline coatings under cathodic protection, Corrosion Engineering Science and Technology, 42 (2007) 42-49.

[20] R.N. Parkins, A Review of Stress Corrosion Cracking of High-Pressure Gas Pipelines, in: CORROSION/2000, NACE International, Houston, TX, 2000.

[21] W. Martyn, E. Brian, J. Tom, W. Robert, Role of coatings in the development of corrosion and 
stress corrosion cracking on gas transmission pipelines. Proceedings of the 1998 International Pipeline Conference, IPC. Part 1, ASME.1998, p 399-403, in, 1998.

[22] A.I. Marshakov, V.E. Ignatenko, R.I. Bogdanov, A.B. Arabey, Effect of electrolyte composition on crack growth rate in pipeline steel, Corrosion Science, 83 (2014) 209-216.

[23] A. Eslami, B. Fang, R. Kania, B. Worthingham, J. Been, R. Eadie, W. Chen, Stress corrosion cracking initiation under the disbonded coating of pipeline steel in near-neutral $\mathrm{pH}$ environment, Corrosion Science, 52 (2010) 3750-3756.

[24] A. Nishikata, Y. Ichihara, T. Tsuru, Electrochemical impedance spectroscopy of metals covered with a thin electrolyte layer, Electrochimica Acta, 41 (1996) 1057-1062.

[25] J. Xu, C. Sun, M. Yan, F. Wang, Electrochemical behavior of steel A36 under disbonded coating in the presence of sulfate-reducing bacteria, Materials Chemistry and Physics, 142 (2013) 692-700.

[26] M. Urquidi-Macdonald, S. Real, D.D. Macdonald, Applications of Kramers—Kronig transforms in the analysis of electrochemical impedance data-III. Stability and linearity, Electrochimica Acta, 35 (1990) 1559-1566.

[27] I. Betova, M. Bojinov, P. Kinnunen, K. Mäkelä, T. Saario, Conduction mechanism in oxide films on ferrous alloys studied by impedance spectroscopy in symmetrical and asymmetrical configurations, Journal of Electroanalytical Chemistry, 572 (2004) 211-223.

[28] I. Nicic, D.D. Macdonald, The passivity of Type 316L stainless steel in borate buffer solution, Journal of Nuclear Materials, 379 (2008) 54-58.

[29] J. Ai, Y. Chen, M. Urquidi-Macdonald, D.D. Macdonald, Electrochemical Impedance Spectroscopic Study of Passive Zirconium: I. High-Temperature, Deaerated Aqueous Solutions, Journal of the Electrochemical Society, 154 (2007) C43-C51.

[30] J. Xu, X. Wu, E.-H. Han, The evolution of electrochemical behaviour and oxide film properties of 304 stainless steel in high temperature aqueous environment, Electrochimica Acta, 71 (2012) $219-226$.

[31] Y. Zhang, C. Yan, F. Wang, W. Li, Electrochemical behavior of anodized Mg alloy AZ91D in chloride containing aqueous solution, Corros Sci, 47 (2005) 2816-2831.

[32] C. Thee, L. Hao, J. Dong, X. Mu, X. Wei, X. Li, W. Ke, Atmospheric corrosion monitoring of a weathering steel under an electrolyte film in cyclic wet-dry condition, Corros Sci, 78 (2014) 130-137. 
[33] B. Rosborg, T. Kosec, A. Kranjc, J. Pan, A. Legat, Electrochemical impedance spectroscopy of pure copper exposed in bentonite under oxic conditions, Electrochimica Acta, 56 (2011) 7862-7870.

[34] R.N. Deo, N. Birbilis, J.P. Cull, Measurement of corrosion in soil using the galvanostatic pulse technique, Corrosion Science, 80 (2014) 339-349.

[35] G. Van Boven, W. Chen, R. Rogge, The role of residual stress in neutral pH stress corrosion cracking of pipeline steels. Part I: Pitting and cracking occurrence, Acta Materialia, 55 (2007) $29-42$.

[36] B.R. Linter, G.T. Burstein, Reactions of pipeline steels in carbon dioxide solutions, Corrosion Science, 41 (1999) 117-139.

[37] J.T. Johnson, C.L. Durr, J.A. Beavers, B.S. Delanty, Effects of O2 and CO2 on near-neutral-pH stress corrosion crack propagation in: Corrosion 2000, NACE International, Houston, Texas, 2000.

[38] A. Eslami, R. Kania, B. Worthingham, G.V. Boven, R. Eadie, W. Chen, Corrosion of X-65 Pipeline Steel Under a Simulated Cathodic Protection Shielding Coating Disbondment, Corrosion, 69 (2013) 1103-1110.

[39] K. Chevil, A. Eslami, W. Chen, R. Eadie, R. Kania, R. Worthingham, G. Van Boven, Developing cathodic protection based on disbondment geometry, in: Proceedings of the 9th International Pipeline Conference, 2012, Vol 2, ASME, Calgary, Alberta, Canada,, 2012, pp. 583-590.

[40] W. Chen, R. Kania, R. Worthingham, G.V. Boven, Transgranular crack growth in the pipeline steels exposed to near-neutral $\mathrm{pH}$ soil aqueous solutions: The role of hydrogen, Acta Materialia, 57 (2009) 6200-6214. 


\section{Figure Captures}

Fig. 1 Geometry of tensile specimen used in this work (all dimension in $\mathrm{mm}$ )

Fig. 2. (a) Schematic representation of the electrochemical system combining a crevice cell and a multi-sample loading frame designed for study stress corrosion of pipeline steel under simulated disbonded coating (b) Top view of the system showing the shielding area, location of segmented specimens and measurement ports

Fig. 3. Kramers-Kronig transforms (the lines) of measured EIS data (the scatters) after 1 day and 120 day test for (a) tensile specimen and (b) unstressed specimen at $25 \mathrm{~cm}$ away from opening. The remarkable coincidence of the measured data and the transformed data exhibits that the system obeys the LST rule

Fig.4. Local potential of X80 steel in the thin electrolyte layer at various distances from the opening in the crevice

Fig.5. Variation of $\mathrm{pH}$ of the thin electrolyte layer under the disbondment at various distances from the opening, the bulk soil solution at the holiday was sparged with 5\% $\mathrm{CO}_{2}+95 \% \mathrm{~N}_{2}$

Fig.6. EIS plots for $\mathrm{X} 80$ steel with $\left(\mathrm{S}_{\mathrm{ys}}\right)$ or without $\left(\mathrm{S}_{0}\right)$ tensile stress after 1 day test at different location under simulated disbonded coating

Fig. 7. EIS plots for $\mathrm{X} 80$ steel with $\left(\mathrm{S}_{\mathrm{ys}}\right)$ or without $\left(\mathrm{S}_{0}\right)$ tensile stress after 15 day test at different location under simulated disbonded coating. The symbols are the measured points, and the lines are the fitted lines

Fig.8. EIS plots for $\mathrm{X} 80$ steel with $\left(\mathrm{S}_{\mathrm{ys}}\right)$ or without $\left(\mathrm{S}_{0}\right)$ tensile stress after 80 day test at different location under simulated disbonded coating. The symbols are the measured points, and the lines are the fitted lines

Fig. 9. EIS plots for $\mathrm{X} 80$ steel with $\left(\mathrm{S}_{\mathrm{ys}}\right)$ or without $\left(\mathrm{S}_{0}\right)$ tensile stress after 120 day test at different location under simulated disbonded coating. The symbols are the measured points, and the lines are the fitted lines

Fig.10. Equivalent electrical circuit used to fit the measured EIS data, where $R_{\mathrm{s}}$ represents the 
solution resistance, $R_{\mathrm{ct}}$ is the charge transfer resistance, and constant phase element (CPE) $Q_{\mathrm{dl}}$ is used as a substitute of the double layer capacitance due to the non-ideal capacitive response of the steel/electrolyte interface

Fig.11. Charge of transfer resistance $R_{\mathrm{ct}}$ for the tensile specimen (a) and the unstressed specimen (b) as a function of the distance from the opening. $R_{\mathrm{ct}}$ was obtained by fitting measured EIS data using the equivalent electrical circuit shown in Fig. 10

Fig.12. $R_{\mathrm{ct}}{ }^{-1}$ for tensile specimen $\left(\mathrm{S}_{\mathrm{ys}}\right)$ and unstressed specimen $\left(\mathrm{S}_{0}\right)$ of X80 steel under simulated disbonded coating as a function of distance from the opening at $1 \mathrm{~d}, 15 \mathrm{~d}$ and $120 \mathrm{~d}$ of the test

Fig.13. Galvanic current between the couple of tensile specimen and unstressed specimen at the opening and under shielding area. Herein, the positive current signifies the anode for the tensile specimen

Fig. 14. SEM micrograph indicating a loose and porous corrosion product layer on the steel surfaces (a, b) at the opening, (c, d) $5 \mathrm{~cm}$ and (e, f) $25 \mathrm{~cm}$ away from the opening

Fig.15. SEM surface morphologies of unstressed specimen with corrosion products removed: (a) at the opening, (b) $5 \mathrm{~cm}$ and (c) $25 \mathrm{~cm}$ away from the opening after 120 day test Fig.16. SEM morphologies of tensile specimens (a, b) $5 \mathrm{~cm}$ and (c, d) $25 \mathrm{~cm}$ away from the opening under disbonded coating: Pitting attack becomes the dominant corrosion form for the tensile specimen $5 \mathrm{~cm}$ away from the opening $(\mathrm{a}, \mathrm{b})$; Some pits occur in clusters and coalesce with each other to form coalesced pitting $(c, d)$

Fig.17. Shielding factor indicating the shielding effect of the disbondment on $R_{\mathrm{ct}}{ }^{-1}$ of the tensile specimen $\left(\mathrm{S}_{\mathrm{ys}}\right)$ and the unstressed specimen $\left(\mathrm{S}_{0}\right)$ as a function of deep/width ratio of the crevice at $15 \mathrm{~d}$ and $120 \mathrm{~d}$ of the test 


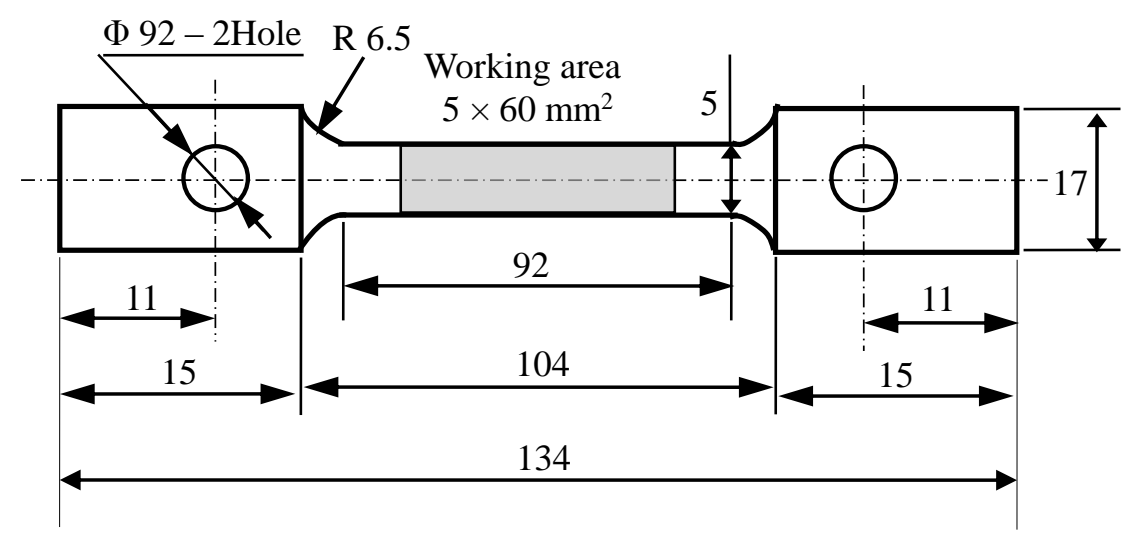

Thinkness: $0.5 \mathrm{~mm}$

Fig.1. Geometry of tensile specimen used in this work (all dimension in $\mathrm{mm}$ ) 
(a)

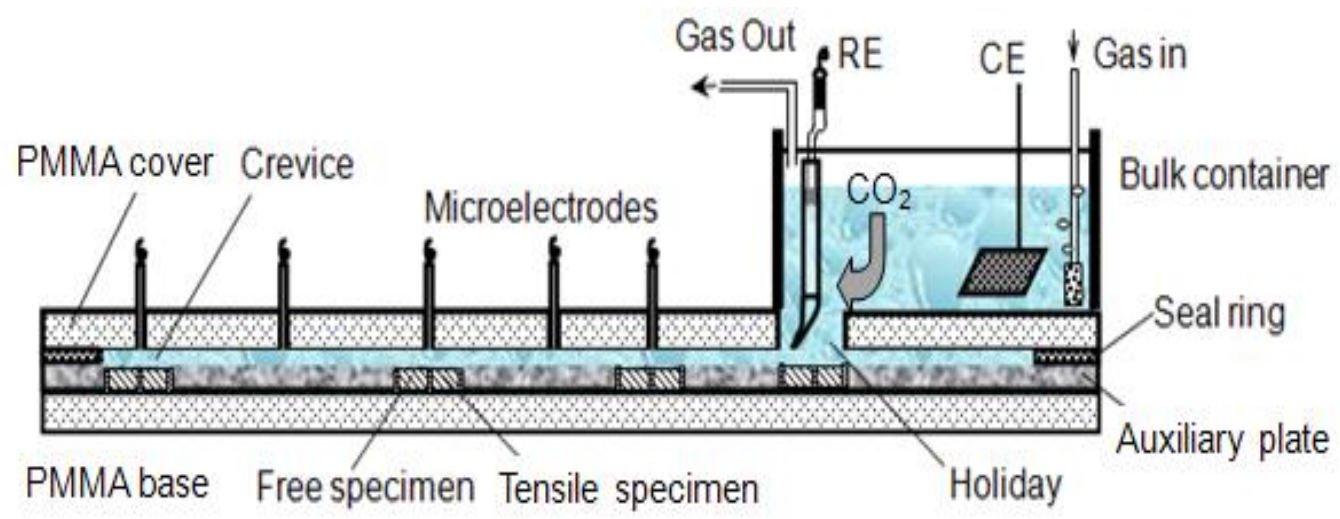

(b)

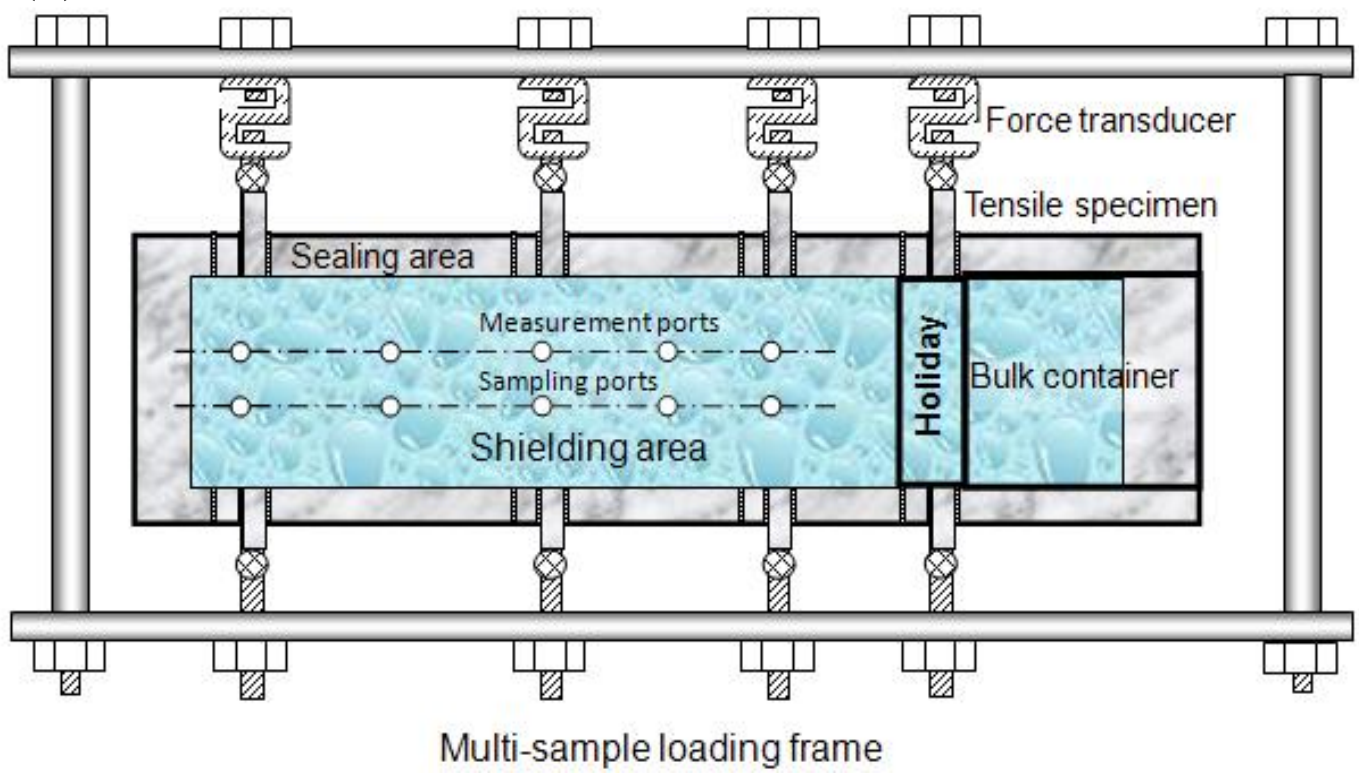

Fig. 2 (a) Schematic representation of the electrochemical system combining a crevice cell and a multi-sample loading frame designed for study stress corrosion of pipeline steel under simulated disbonded coating (b) Top view of the system showing the shielding area, location of segmented specimens and measurement ports 


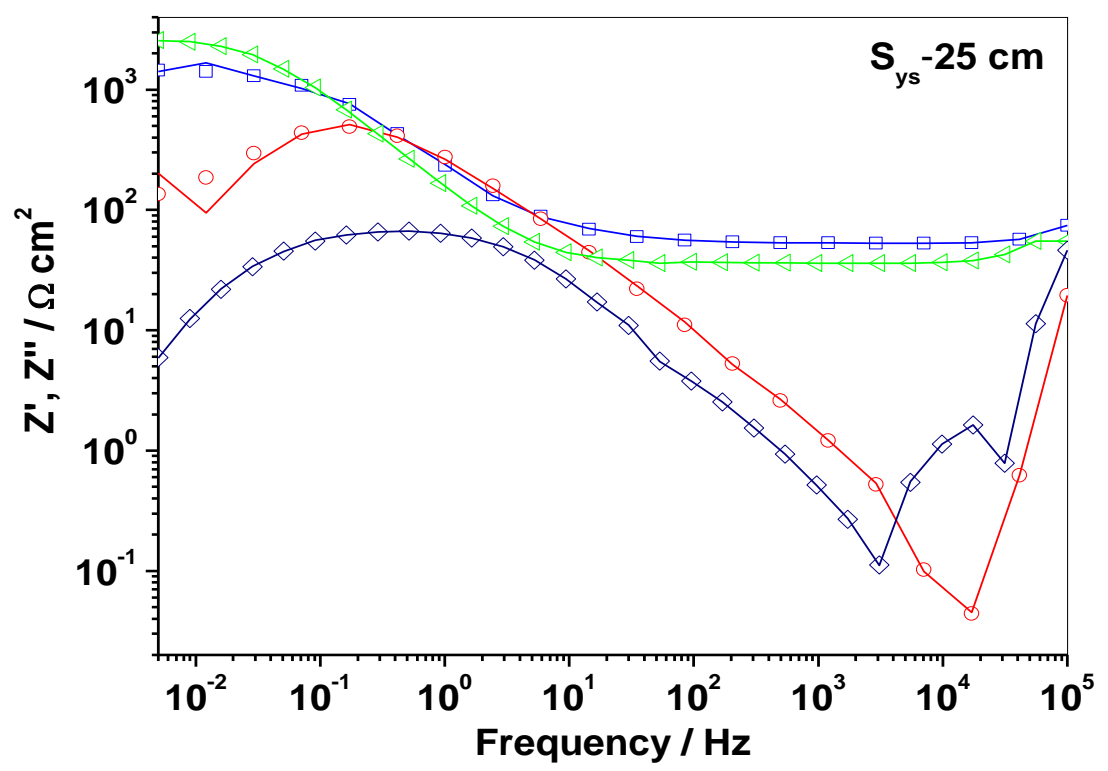

$1 \mathrm{~d}$

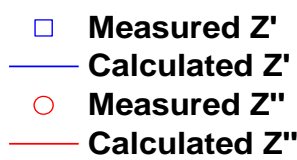

$120 \mathrm{~d}$

Measured Z'

Calculated ' Z'

Measured Z"

Calculated Z"

Calculated Z"



Fig. 3 Kramers-Kronig transforms (the lines) of measured EIS data (the scatters) after 1 day and 120 day test for (a) tensile specimen and (b) unstressed specimen at $25 \mathrm{~cm}$ away from opening. The remarkable coincidence of the measured data and the transformed data exhibits that the system obeys the LST rule 


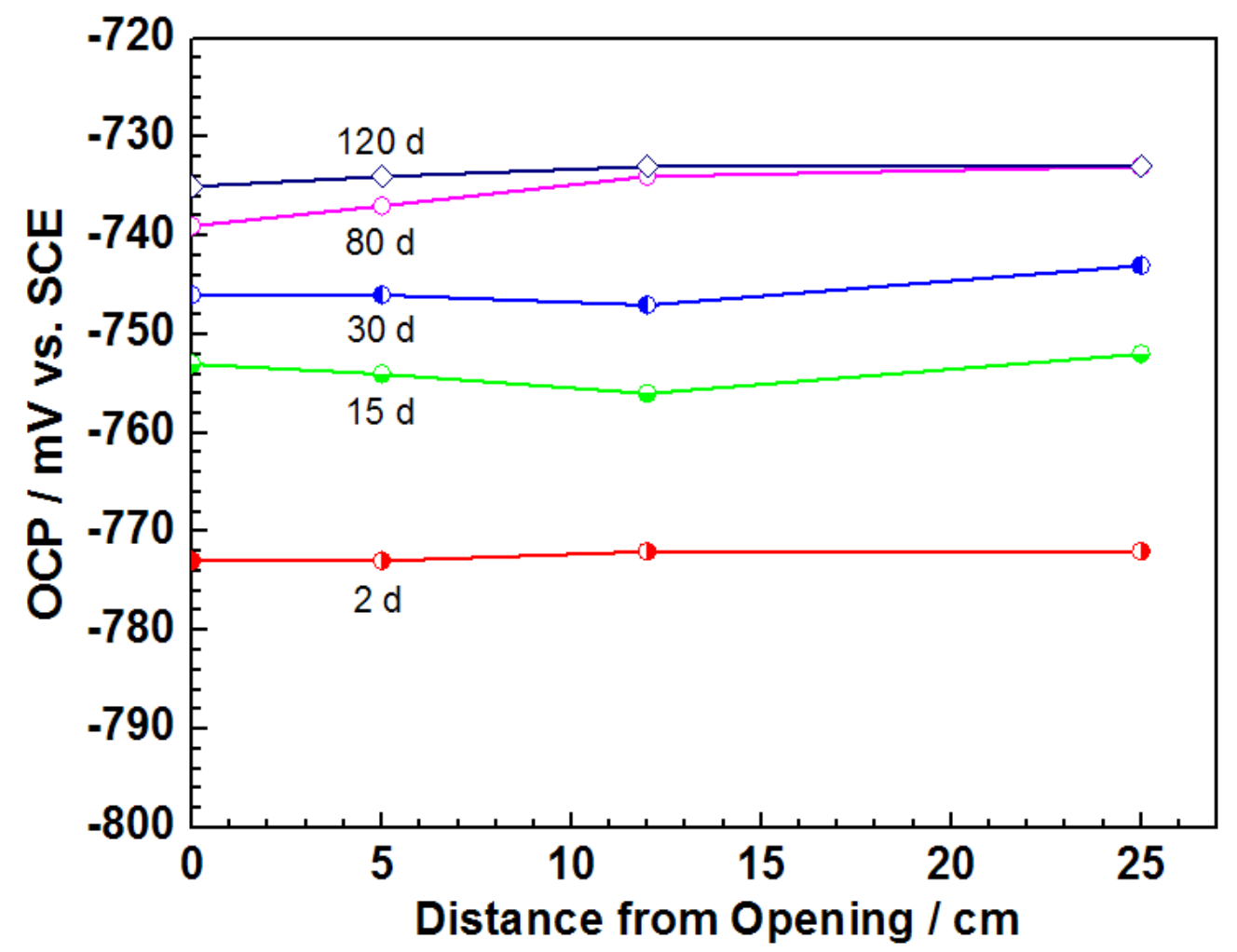

Fig.4. Local potential of X80 steel in the thin electrolyte layer at various distances from the opening in the crevice 


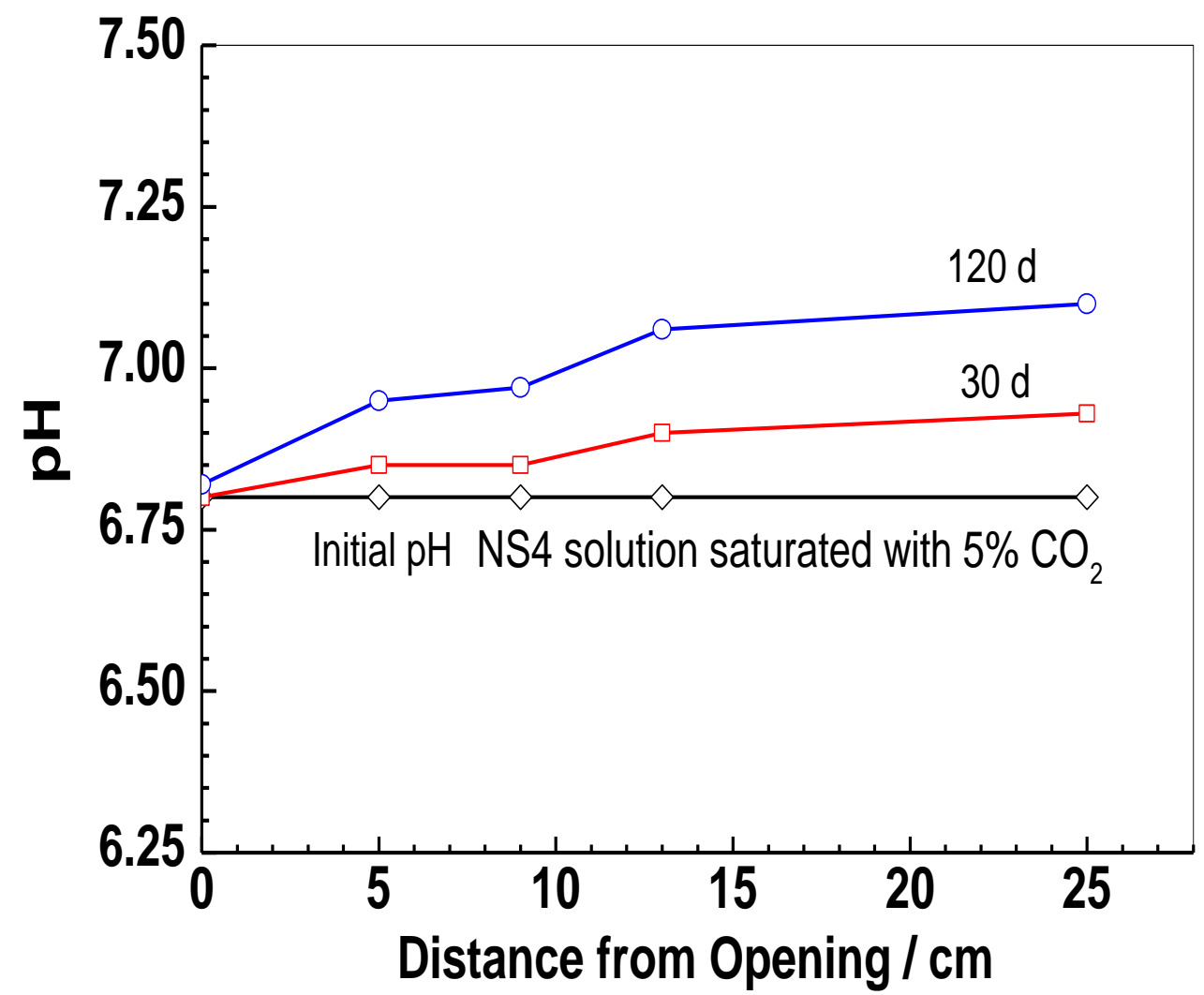

Fig.5 Variation of $\mathrm{pH}$ of the thin electrolyte layer under the disbondment at various distances from the opening, the bulk soil solution at the holiday was sparged with $5 \% \mathrm{CO}_{2}+95 \% \mathrm{~N}_{2}$ 

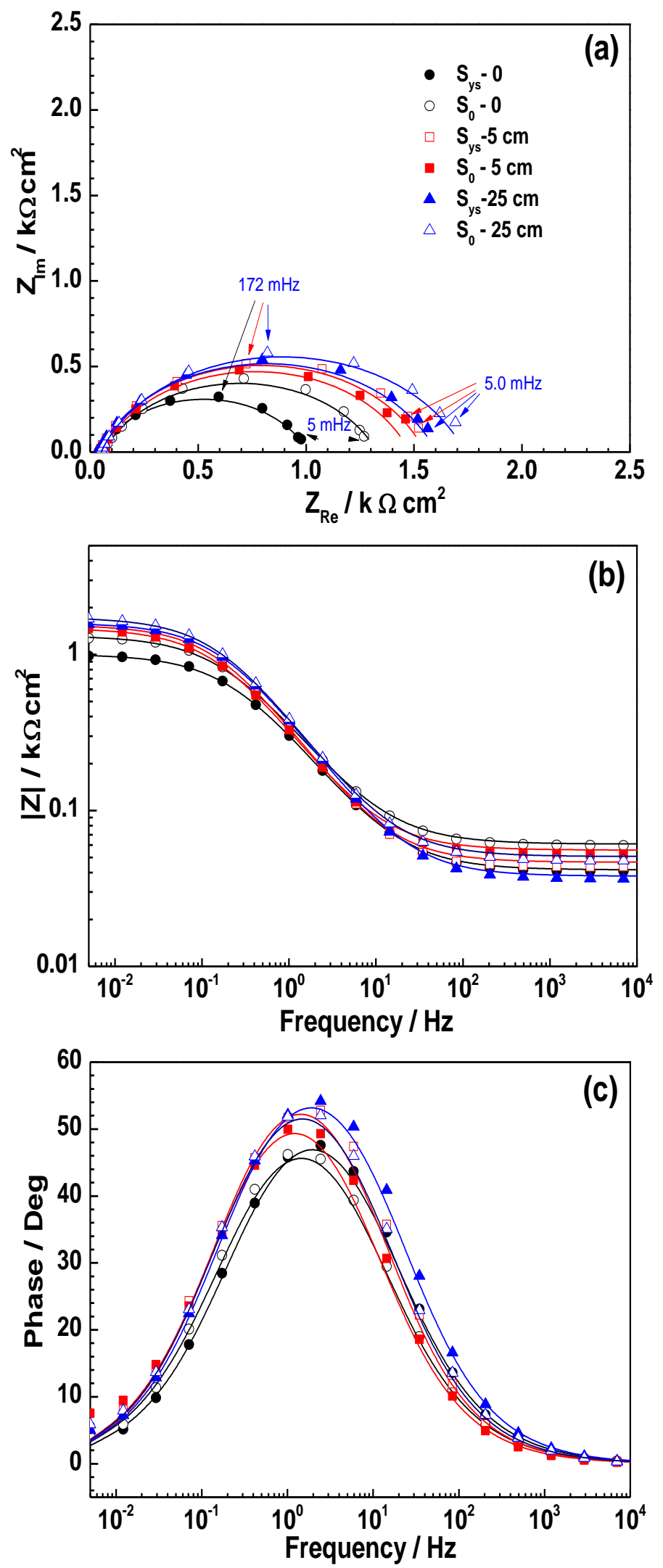

Fig.6. EIS plots for $\mathrm{X} 80$ steel with $\left(\mathrm{S}_{\mathrm{ys}}\right)$ or without $\left(\mathrm{S}_{0}\right)$ tensile stress after 1 day test at different location under simulated disbonded coating. The symbols are the measured points and the lines are the fitted lines 



Fig.7. EIS plots for $\mathrm{X} 80$ steel with $\left(\mathrm{S}_{\mathrm{ys}}\right)$ or without $\left(\mathrm{S}_{0}\right)$ tensile stress after 15 day test at different location under simulated disbonded coating. The symbols are the measured points, and the lines are the fitted lines 



Fig.8. EIS plots for $\mathrm{X} 80$ steel with $\left(\mathrm{S}_{\mathrm{ys}}\right)$ or without $\left(\mathrm{S}_{0}\right)$ tensile stress after 80 day test at different location under simulated disbonded coating. The symbols are the measured points, and the lines are the fitted lines 



Fig.9. EIS plots for $\mathrm{X} 80$ steel with $\left(\mathrm{S}_{\mathrm{ys}}\right)$ or without $\left(\mathrm{S}_{0}\right)$ tensile stress after 120 day test at different location under simulated disbonded coating. The symbols are the measured points, and the lines are the fitted lines 


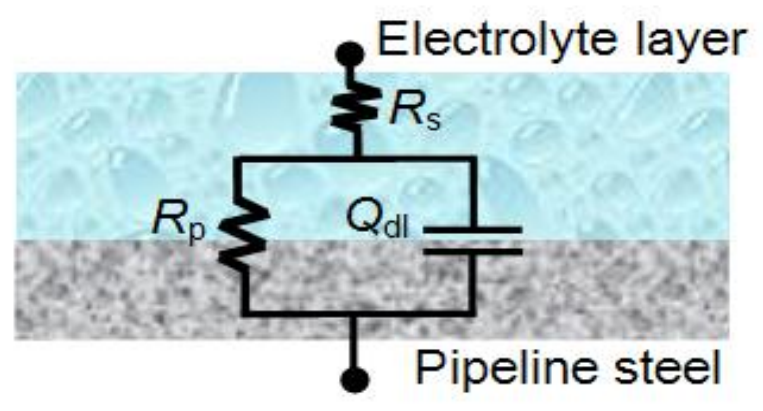

Fig.10. Equivalent electrical circuit used to fit the measured EIS data, where $R_{\mathrm{s}}$ represents the solution resistance, $R_{\mathrm{ct}}$ is the charge transfer resistance, and constant phase element (CPE) $Q_{\mathrm{dl}}$ is used as a substitute of the double layer capacitance due to the non-ideal capacitive response of the steel/electrolyte interface 

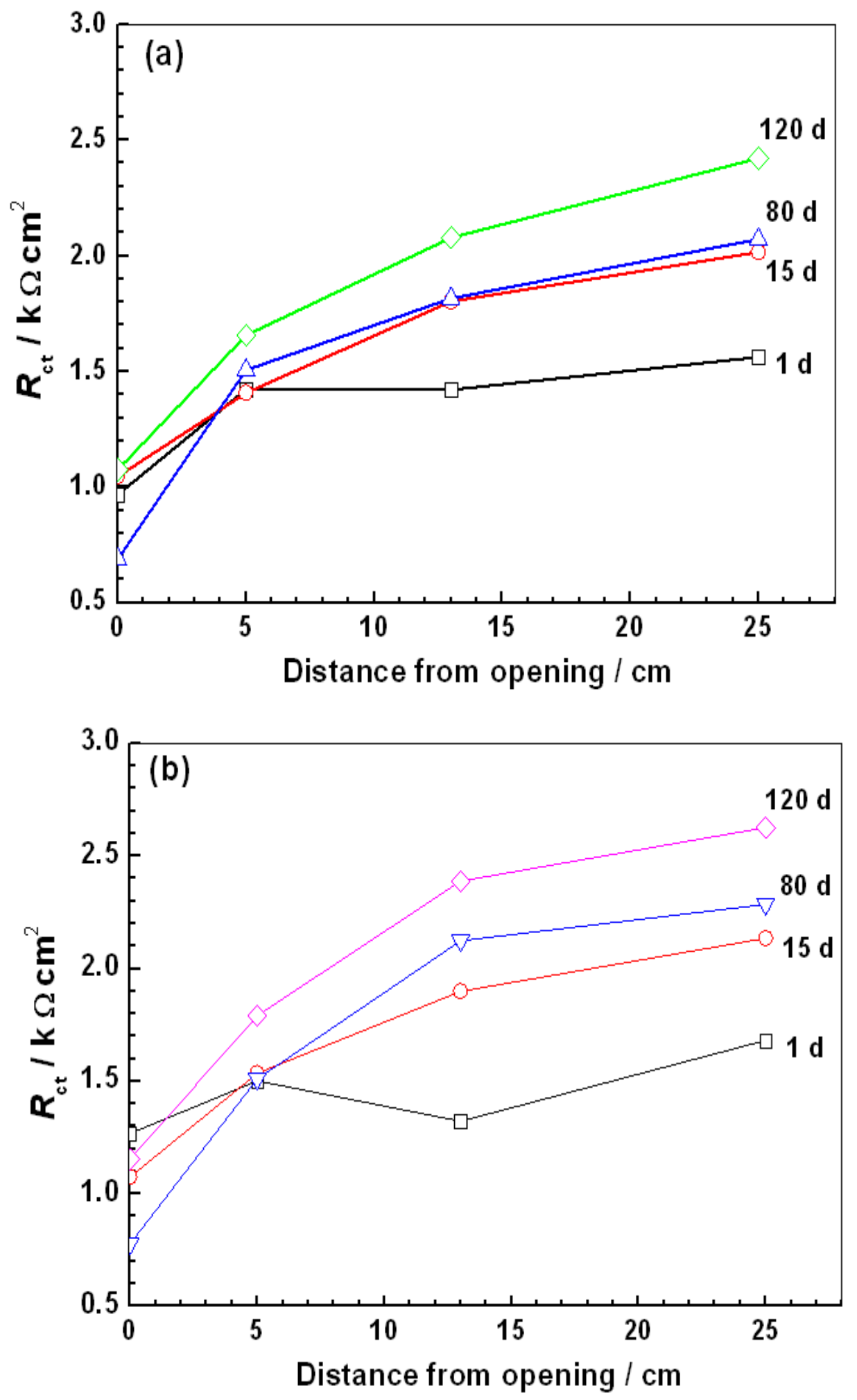

Fig.11. Charge of transfer resistance $R_{\mathrm{ct}}$ for the tensile specimen (a) and the unstressed specimen (b) as a function of the distance from the opening. $R_{\mathrm{ct}}$ was obtained by fitting measured EIS data using the equivalent electrical circuit shown in Fig. 10. 


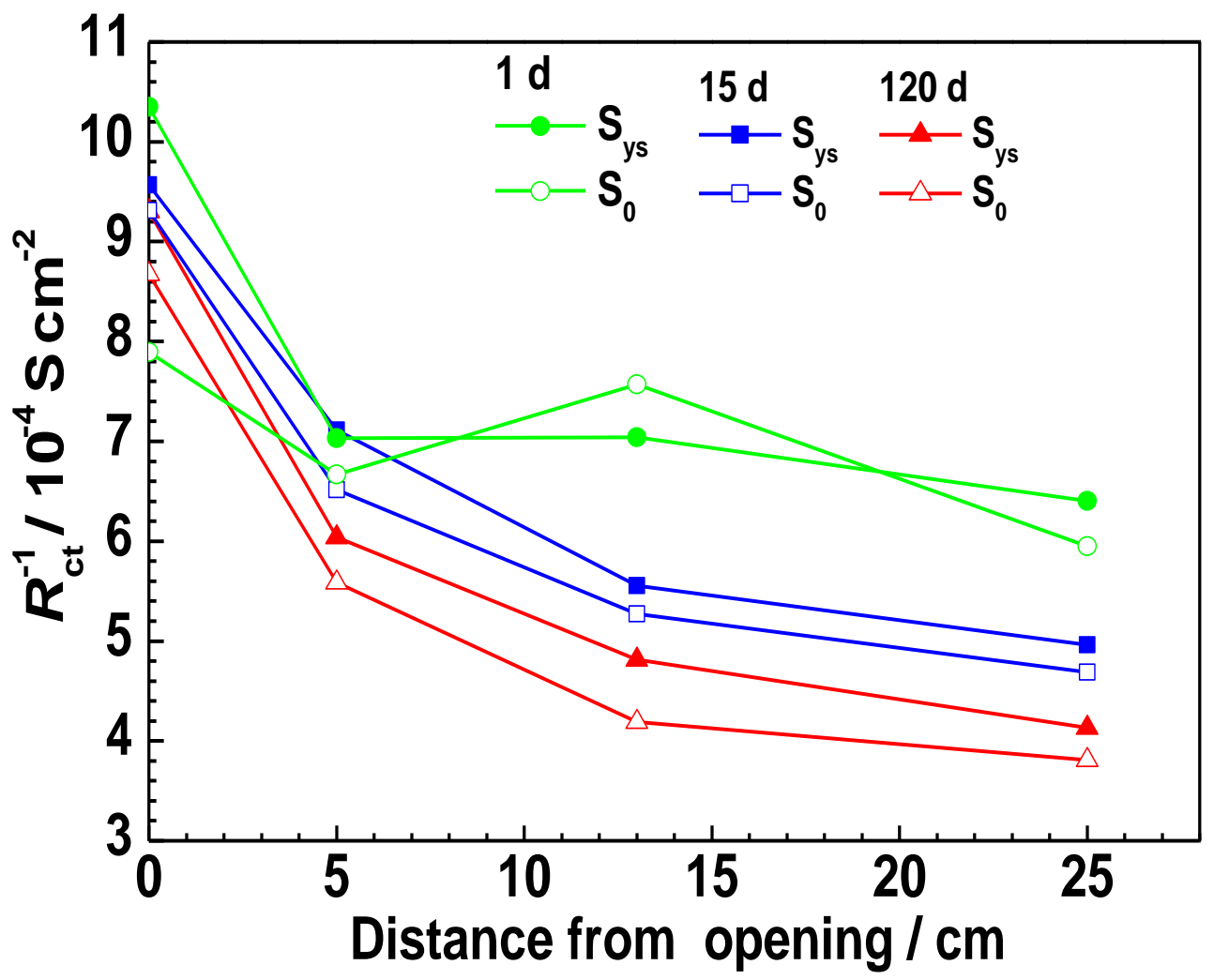

Fig.12. $R_{\mathrm{ct}}^{-1}$ for tensile specimen $\left(\mathrm{S}_{\mathrm{ys}}\right)$ and unstressed specimen $\left(\mathrm{S}_{0}\right)$ of $\mathrm{X} 80$ steel under simulated disbonded coating as a function of distance from the opening at $1 \mathrm{~d}, 15 \mathrm{~d}$ and $120 \mathrm{~d}$ of the test 


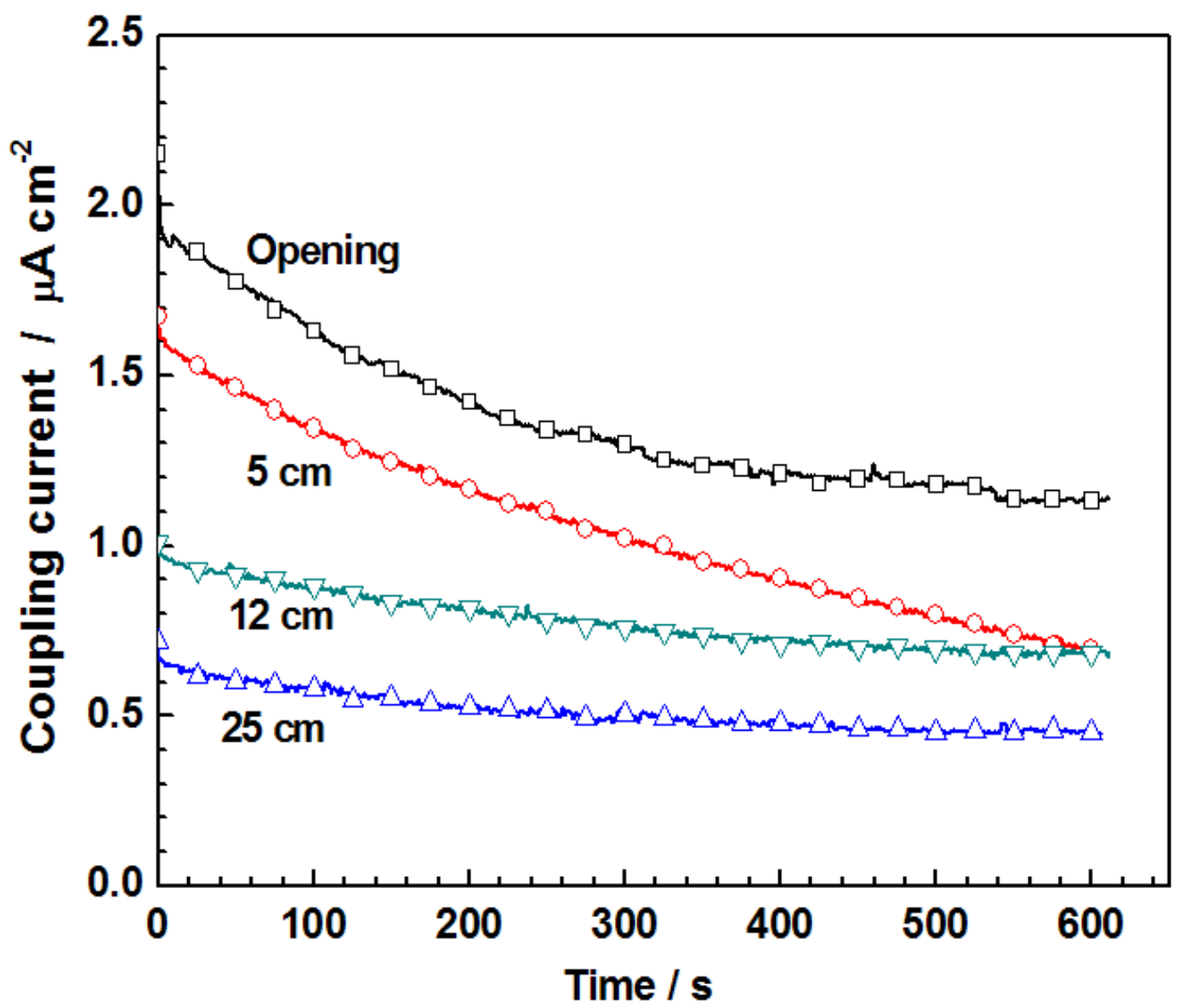

Fig. 13. Galvanic current between the couple of tensile specimen and unstressed specimen at the opening and under shielding area. Herein, the positive current signifies the anode for the tensile specimen 

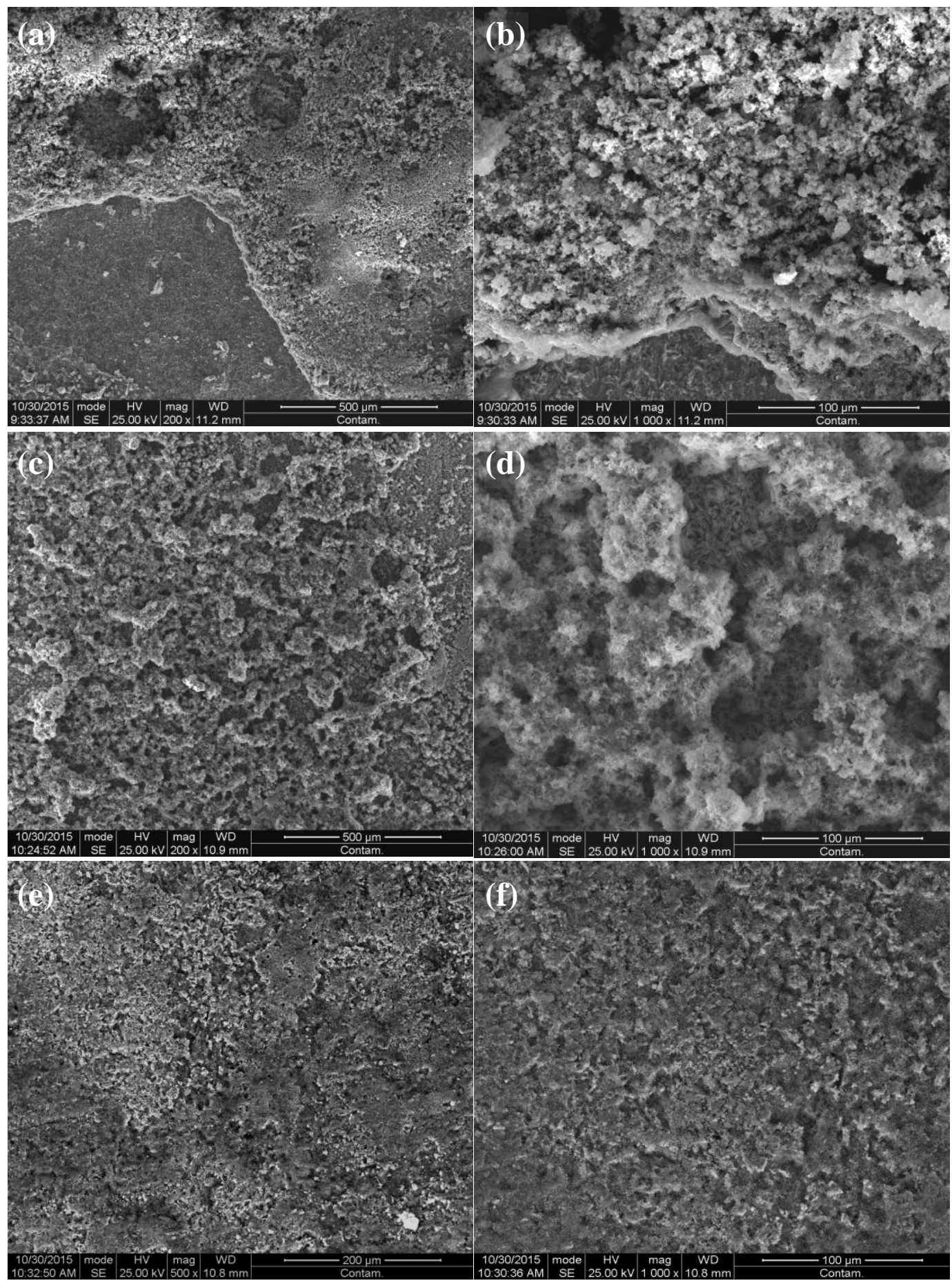

Fig. 14. SEM micrograph indicating a loose and porous corrosion product layer on the steel surfaces (a, b) at the opening, (c, d) $5 \mathrm{~cm}$ and (e, f) $25 \mathrm{~cm}$ away from the opening 

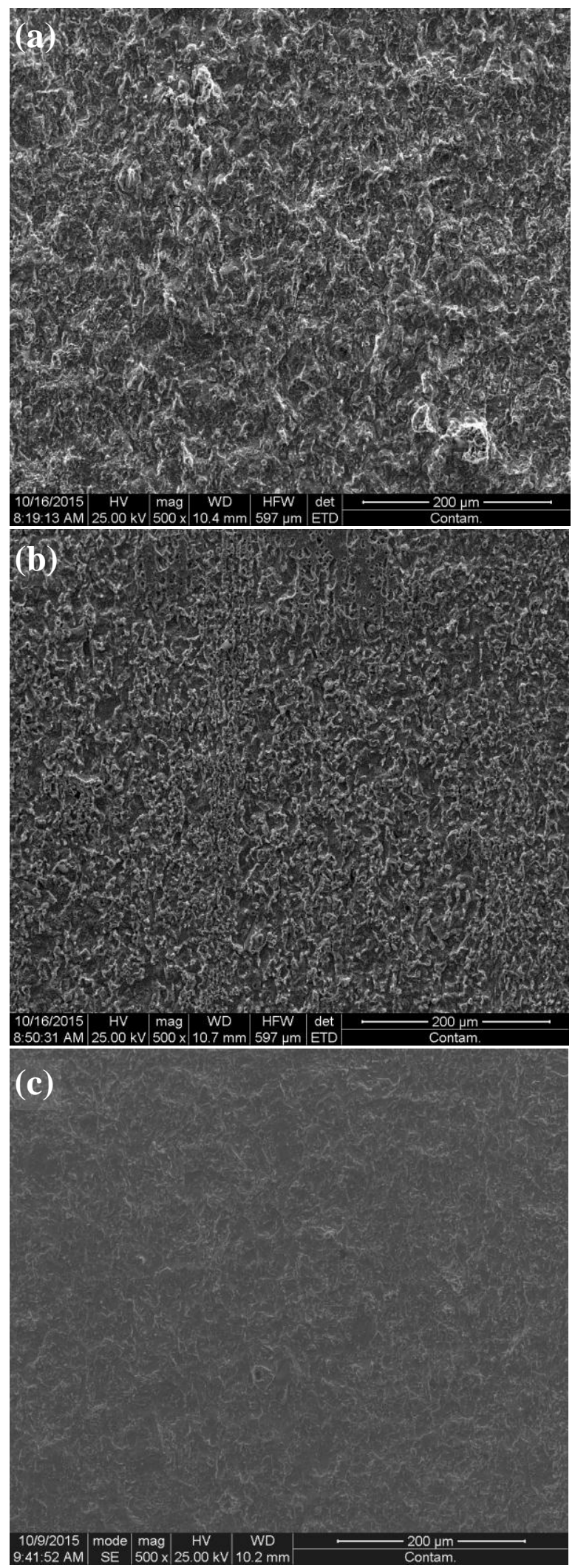

Fig.15. SEM surface morphologies of unstressed specimen with corrosion products removed: (a) at the opening, (b) $5 \mathrm{~cm}$ and (c) $25 \mathrm{~cm}$ away from the opening after 120 day test 

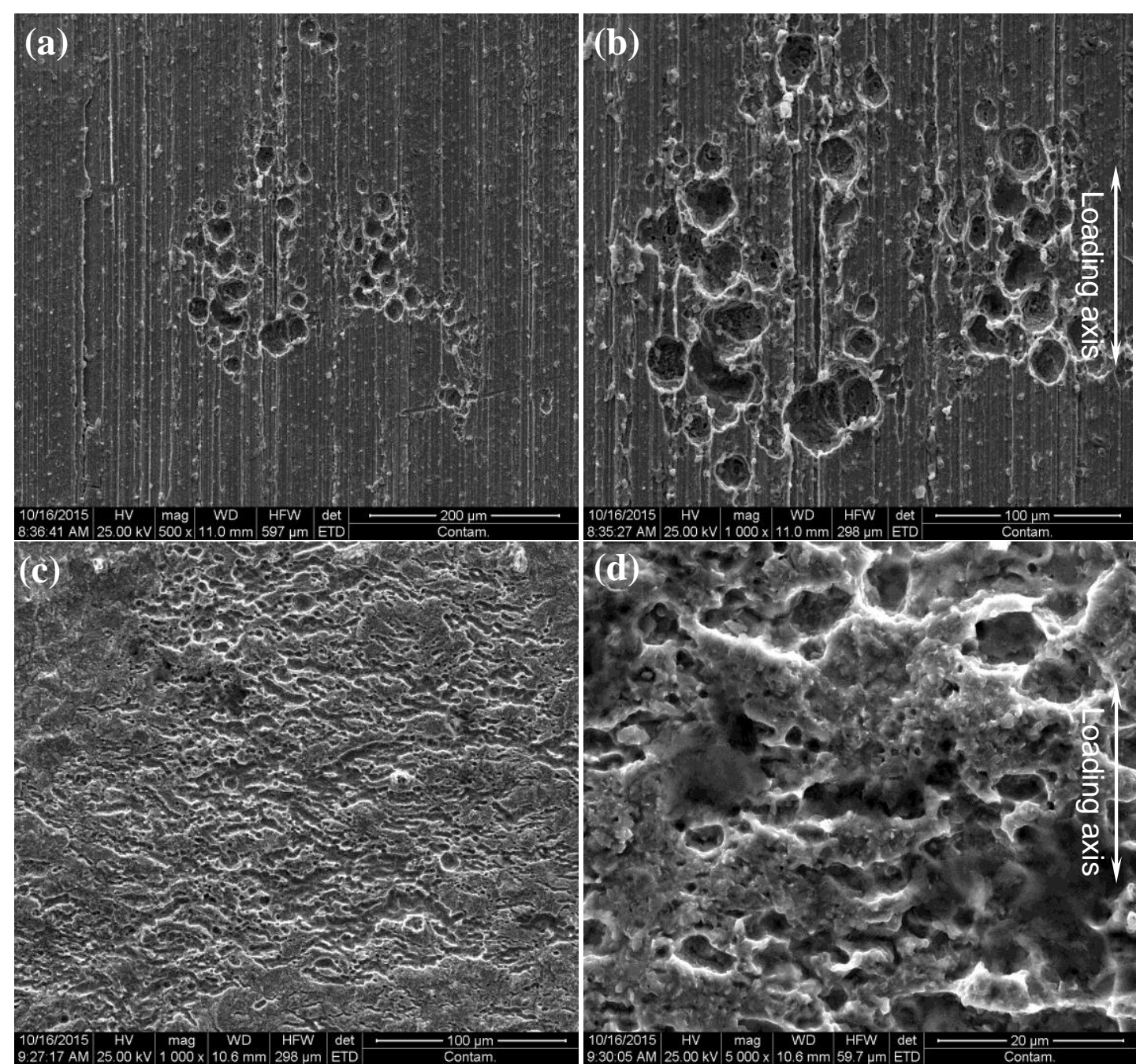

Fig.16. SEM morphologies of the tensile specimens (a, b) $5 \mathrm{~cm}$ and (c, d) $25 \mathrm{~cm}$ away from the opening under disbonded coating: Pitting attack becomes the dominant corrosion form for the tensile specimen $5 \mathrm{~cm}$ away from the opening $(\mathrm{a}, \mathrm{b})$; Some pits occur in clusters and coalesce with each other to form coalesced pitting (c, d) 


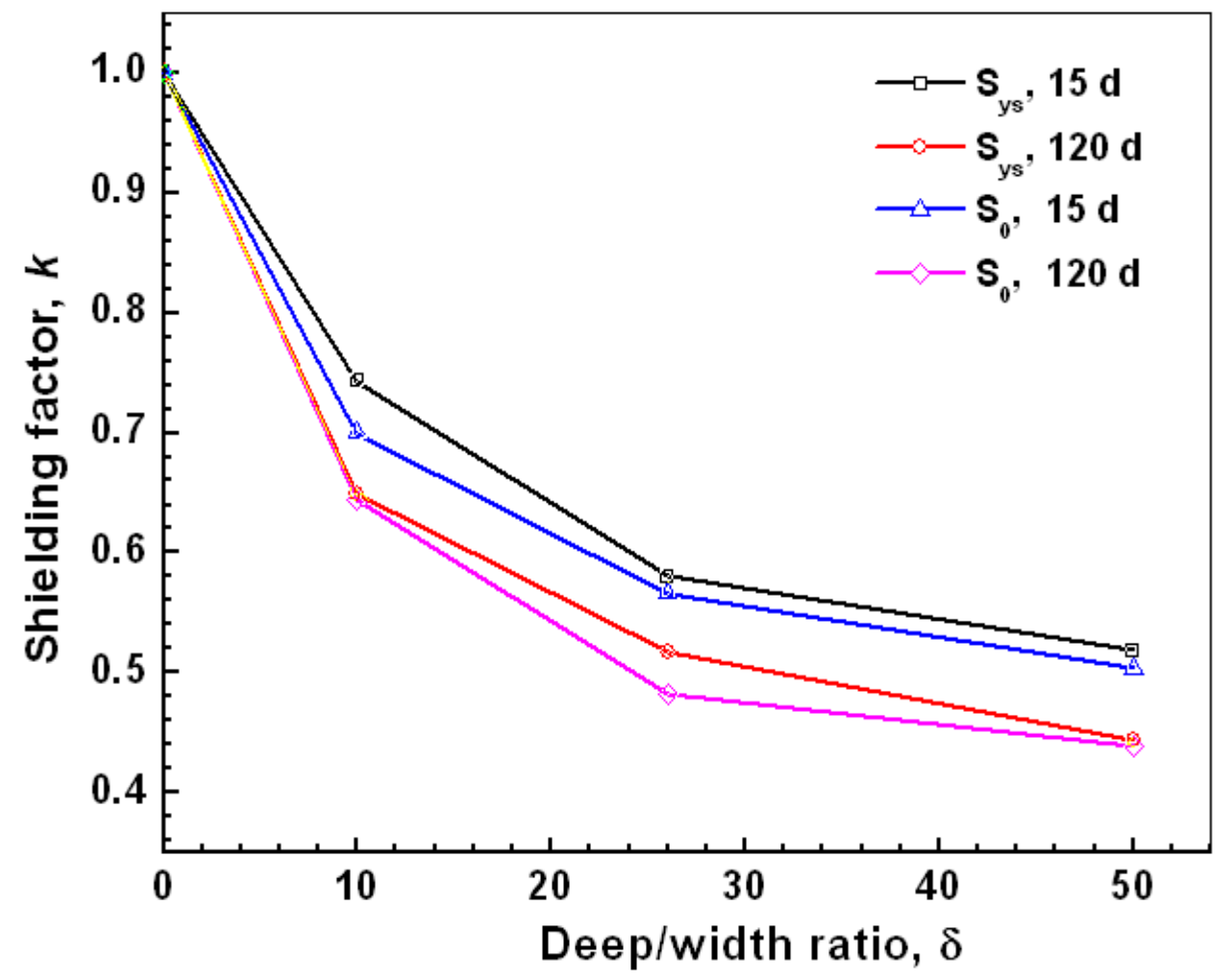

Fig.17. Shielding factor indicating the shielding effect of disbondment on $R_{\mathrm{ct}}{ }^{-1}$ of the tensile specimen $\left(\mathrm{S}_{\mathrm{ys}}\right)$ and the unstressed specimen $\left(\mathrm{S}_{0}\right)$ as a function of deep/width ratio of the crevice at $15 \mathrm{~d}$ and $120 \mathrm{~d}$ of the test 
Table 1

Chemical compositions (wt. \%) of X80 pipeline steel used in this work

\begin{tabular}{cccccccc}
\hline $\mathrm{C}$ & $\mathrm{Mn}$ & $\mathrm{Si}$ & $\mathrm{P}$ & $\mathrm{S}$ & $\mathrm{Mo}$ & $\mathrm{Ni}$ & $\mathrm{Cr}$ \\
\hline 0.07 & 1.82 & 0.19 & 0.007 & 0.023 & 0.010 & 0.17 & 0.026 \\
\hline $\mathrm{Cu}$ & $\mathrm{V}$ & $\mathrm{Nb}$ & $\mathrm{Ti}$ & $\mathrm{Al}$ & $\mathrm{N}$ & $\mathrm{B}$ & $\mathrm{Fe}$ \\
\hline 0.020 & 0.002 & 0.056 & 0.012 & 0.028 & 0.004 & 0.0001 & Bal. \\
\hline
\end{tabular}


Table 2

Fitted EIS parameters of X80 pipeline steel during test under simulated disbonded coating

\begin{tabular}{|c|c|c|c|c|c|c|c|c|c|}
\hline \multirow[b]{3}{*}{ Position } & \multicolumn{3}{|c|}{ Tensile specimen } & \multicolumn{6}{|c|}{ Unstressed specimen } \\
\hline & \multirow{2}{*}{$\begin{array}{l}\text { Time } \\
\mathrm{d}\end{array}$} & \multirow{2}{*}{$\begin{array}{l}\boldsymbol{R}_{\mathrm{s}} \\
\Omega \mathrm{cm}^{2}\end{array}$} & \multicolumn{2}{|l|}{$Q_{\mathrm{dl}}$} & \multirow{2}{*}{$\begin{array}{l}R_{\mathrm{ct}} \\
\mathrm{k} \Omega \mathrm{cm}^{2}\end{array}$} & \multirow{2}{*}{$\begin{array}{l}\boldsymbol{R}_{\mathrm{s}} \\
\Omega \mathrm{cm}^{2}\end{array}$} & \multicolumn{2}{|l|}{$Q_{\mathrm{dl}}$} & \multirow{2}{*}{$\begin{array}{l}\boldsymbol{R}_{\mathrm{ct}} \\
\mathrm{k} \Omega \mathrm{cm}^{2}\end{array}$} \\
\hline & & & $\overline{Y_{0}\left(\mathrm{~S} \mathrm{~s}^{n} \mathrm{~cm}^{-2}\right)}$ & $n$ & & & $\overline{Y_{0}\left(\mathrm{~S} \mathrm{~s}^{n} \mathrm{~cm}^{-2}\right)}$ & $n$ & \\
\hline \multirow{4}{*}{ Opening } & 1 & 41.50 & $7.733 \times 10^{-4}$ & 0.7526 & 0.9662 & 60.82 & $7.028 \times 10^{-4}$ & 0.7487 & 1.267 \\
\hline & 15 & 50.36 & $8.736 \times 10^{-4}$ & 0.8444 & 1.045 & 71.10 & $8.824 \times 10^{-4}$ & 0.8011 & 1.074 \\
\hline & 83 & 54.89 & $1.970 \times 10^{-3}$ & 0.8996 & 0.7780 & 71.25 & $1.890 \times 10^{-3}$ & 0.8771 & 0.6886 \\
\hline & 120 & 55.88 & $2.550 \times 10^{-3}$ & 0.9085 & 1.075 & 66.58 & $2.240 \times 10^{-3}$ & 0.8819 & 1.153 \\
\hline \multirow{4}{*}{$5 \mathrm{~cm}$} & 1 & 46.53 & $6.811 \times 10^{-4}$ & 0.7886 & 1.500 & 55.64 & $7.468 \times 10^{-4}$ & 0.7761 & 1.422 \\
\hline & 15 & 50.64 & $7.273 \times 10^{-4}$ & 0.8312 & 1.406 & 64.52 & $7.489 \times 10^{-4}$ & 0.8312 & 1.535 \\
\hline & 83 & 52.35 & $1.100 \times 10^{-3}$ & 0.8977 & 1.510 & 66.32 & $1.310 \times 10^{-3}$ & 0.9008 & 1.505 \\
\hline & 120 & 50.63 & $1.260 \times 10^{-3}$ & 0.8978 & 1.790 & 64.20 & $1.550 \times 10^{-3}$ & 0.9109 & 1.656 \\
\hline \multirow{4}{*}{$25 \mathrm{~cm}$} & 1 & 37.92 & $6.076 \times 10^{-4}$ & 0.7753 & 1.562 & 50.64 & $6.106 \times 10^{-4}$ & 0.7755 & 1.681 \\
\hline & 15 & 40.30 & $7.914 \times 10^{-4}$ & 0.7966 & 2.134 & 57.12 & $9.279 \times 10^{-4}$ & 0.7669 & 2.015 \\
\hline & 83 & 35.44 & $8.262 \times 10^{-4}$ & 0.8797 & 2.285 & 53.50 & $9.436 \times 10^{-4}$ & 0.8454 & 2.070 \\
\hline & 120 & 39.66 & $9.808 \times 10^{-4}$ & 0.8339 & 2.625 & 42.67 & $1.090 \times 10^{-3}$ & 0.8420 & 2.421 \\
\hline
\end{tabular}

